\title{
Atrial arrhythmias after lung transplant: A call to action starting with the electrocardiogram
}

\author{
Marye J. Gleva, MD, ${ }^{a}$ and Charles B. Huddleston, $\mathrm{MD}^{\mathrm{b}}$
}

\footnotetext{
From the ${ }^{\mathrm{a} D i v i s i o n}$ of Cardiology, Washington University School of Medicine; and ${ }^{\mathrm{b}}$ Department of Surgery, Saint Louis University School of Medicine, St Louis, Mo.

Disclosures: Authors have nothing to disclose with regard to commercial support.

Received for publication May 22, 2016; accepted for publication May 26, 2016; available ahead of print June 18, 2016.

Address for reprints: Charles B. Huddleston, MD, 1465 S Grand Blvd, St Louis, MO 63104 (E-mail: chuddle7@ slu.edu).

J Thorac Cardiovasc Surg 2016;152:910-1

$0022-5223 / \$ 36.00$

Copyright (c) 2016 by The American Association for Thoracic Surgery

http://dx.doi.org/10.1016/j.jtcvs.2016.05.043
}

In this issue of the Journal, D'Angelo and colleagues ${ }^{1}$ published their evaluation of the impact of atrial arrhythmias (AAs) occurring in the first month after lung transplantation in adults. The survival over the ensuing 5 years was significantly worse in those with early AAs than in those who maintained normal sinus rhythm. This was noted despite the fact that all those with AAs ultimately converted back to normal sinus rhythm ("confirmed" by physical examination) before discharge from the hospital. The arrhythmias were presumably atrial flutter and atrial fibrillation. Advanced age and prior coronary artery bypass surgery were risk factors for the development of AAs. A history of AAs was protective against post-transplant arrhythmias, possibly the consequence of treatment of the AAs. There are multiple questions raised by this study. (1) What are the AAs specifically? (2) Why do AAs occur after lung transplantation? (3) Why is the survival worse for those with post-transplant AAs? (4) What can be done to prevent the arrhythmias? (5) What should be done for treatment? In any analysis of AAs, the answer to question 1 is imperative because it affects the subsequent approach to evaluation and management. Despite detailed definitions of AAs in the Society of Thoracic Surgeons data dictionary, this study did not differentiate between them, the justification being historical precedent. It is time to channel the power of the Society of Thoracic Surgeons and adopt similar precision.

Atrial fibrillation is relatively common after a variety of major operations, particularly in elderly adults with an incidence of $30 \%$ after coronary artery bypass surgery, ${ }^{2}$ $20 \%$ after thoracotomy with lobectomy, ${ }^{3}$ and $12 \%$ after open repair of an abdominal aortic aneurysm. ${ }^{4}$ The precise reason for atrial fibrillation after any of these has not been determined. Measures to prevent atrial fibrillation, particularly after coronary artery bypass surgery, have been studied extensively with a variety of randomized studies without a clear consensus. The technique for the pulmonary venous anastomosis in lung transplantation involves excision of the orifices of the pulmonary veins

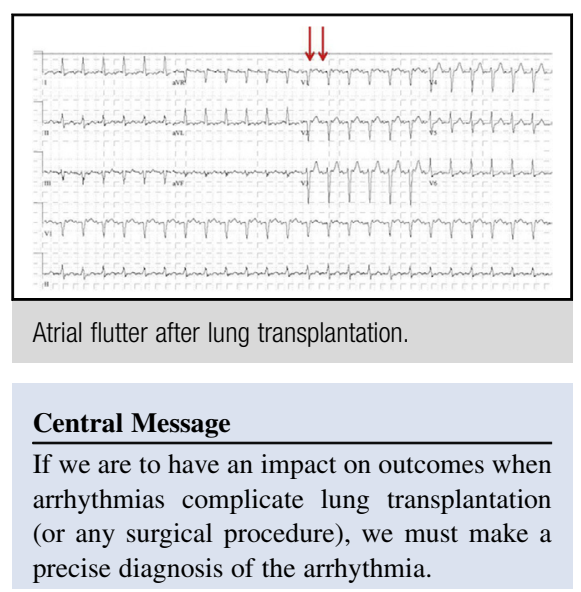

See Article page 901

along with the intervening atrial tissue on each side and sewing the pulmonary venous cuff to the remaining lateral atrial wall; this is the ultimate form of pulmonary vein isolation, a relatively common procedure performed for the treatment of atrial fibrillation. ${ }^{5}$ A study by Gandhi and colleagues, ${ }^{6}$ of an animal model of the atrial incisions associated with lung transplantation, found that these incisions actually provide the substrate for atrial flutter, the mechanism being a reentrant circuit around the area of conduction block produced by the atrial suture lines for the pulmonary venous anastomoses. Further, they noted that the conduction from the left atrium to the right atrium was not consistently 1:1, producing irregular R-R intervals mimicking atrial fibrillation. This "left atrium flutter" results in atypical "flutter" waves on the surface electrocardiagram (Figure 1). It is attractive to ascribe the AAs after lung transplantation to this mechanism because the "cure" for it can be obtained with radiofrequency catheter ablation in the electrophysiology laboratory.

Why is the long-term survival affected by AAs occurring in the early post-transplant period? In general, people do not die of lone atrial fibrillation, but rather as a result of the associated cardiac comorbidities. ${ }^{7}$ In this study, echocardiographic measures such as left atrium size and volume and left ventricular ejection fraction were not collected or reported, and cardiac catheterization was performed more than 1 year before transplant. Thus, no assessment of myocardial substrate is available to evaluate the proper context for these AAs. The causes of death in the group reported by D'Angelo and colleagues ${ }^{1}$ are not 


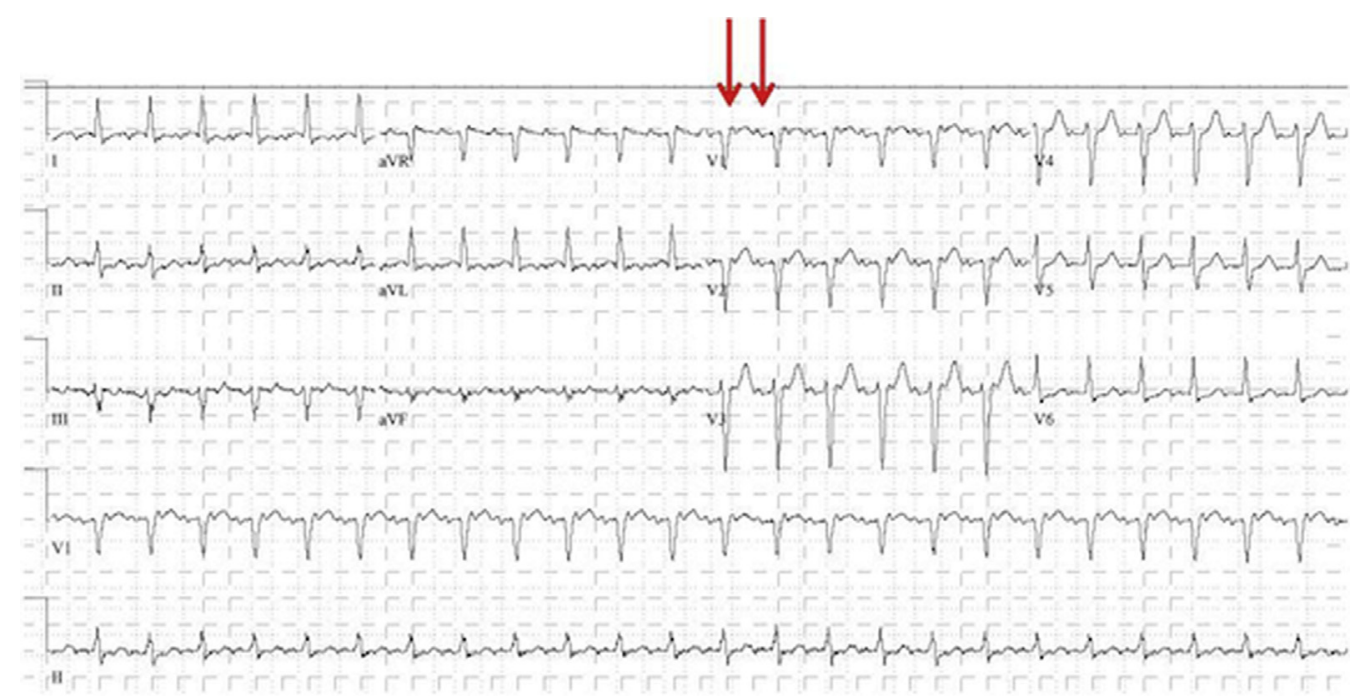

FIGURE 1. This is a 12-lead electrocardiogram from a patient in atrial flutter after lung transplantation. This has an atypical pattern of "p" waves compared with the more typical electrocardiogram in atrial flutter.

provided. The most likely explanation must be that the development of AAs serves as a marker of underlying cardiovascular risk. However, given the limitations of this analysis, one cannot exclude the possibility that the treatment of the AAs or some other unidentified factor accounts for the risk. It should be noted that other studies of AAs after lung transplantation have not shown a reduced survival. ${ }^{8}$ How could treatment for AAs reduce survival? One would think that efforts to maintain sinus rhythm would enhance survival of individuals with AA. Antiarrhythmic drugs, even digoxin, ${ }^{9}$ are known associates with increased mortality in other populations. There is also a case report of amiodarone toxicity in a patient with AAs after lung transplantation. ${ }^{10}$

The bottom line from the study by D'Angelo and colleagues $^{1}$ is that the development of AAs after lung transplant is associated with a longer intensive care unit stay, longer hospital stay, and worse survival. Why the survival is worse cannot be adequately addressed in the current analysis. Pretreatment in those at risk (age $>60$ years and history of coronary artery disease) may blunt this effect. As emphasized, any future evaluation mandates specificity of rhythm diagnosis and rigorous collection of objective data and known cardiac associations. Normal sinus rhythm is a diagnosis best made by electrocardiogram and not physical examination.

\section{References}

1. D'Angelo AM, Chan EG, Hayanga JWA, Odell DD, Pilewski J, Crespo M, et al. Atrial arrhythmias following lung transplantation: incidence and risk factors in 652 lung transplant recipients. J Thorac Cardiovasc Surg. 2016; 152:901-9.

2. Hogue CW, Creswell LL, Gutterman DD, Fleisher LA. Epidemiology, mechanisms, and risks: American College of Chest Physicians guidelines for the prevention and management of postoperative atrial fibrillation after cardiac surgery. Chest. 2005;128:9S-16S.

3. Vaporciyan AA, Correa AM, Rice DC, Roth JA, Smythe WR, Swisher SG, et al. Risk factors associated with atrial fibrillation after noncardiac thoracic surgery: analysis of 2588 patients. J Thorac Cardiovasc Surg. 2004;127:779-86.

4. Noorani A, Walsh SR, Tang TY, Sadat U, Cooper DG, Callaghan CJ, et al. Atrial fibrillation following elective open abdominal aortic aneurysm repair. Int J Surg. 2009; 7:24-7.

5. Weerasooriya R, Khairy P, Litalien J, Macle L, Hocini M, Sacher F, et al. Catheter ablation for atrial fibrillation: are results maintained at 5 years of follow-up? J Am Coll Cardiol. 2011;57:160-6.

6. Gandhi SK, Bromberg BI, Schuessler RM, Boineau JP, Cox JL, Huddleston CB. Left-sided atrial flutter: characterization of a novel complication of pediatric lung transplantation in an acute canine model. J Thorac Cardiovasc Surg. 1996;112: 992-1001.

7. Jahingir A, Lee V, Friedman PA, Trusty JM, Hodge DO, Kopecky SL, et al. Long-term progression and outcomes with aging in patients with lone atria fibrillation: a 30-year follow-up study. Circulation. 2007;115:3050-6.

8. Mason DP, Marsh DH, Alster JM, Murthy SC, McNeill AM, Budev MM, et al. Atrial fibrillation after lung transplantation: timing, risk factors and treatment. Ann Thorac Surg. 2007:84:1878-84.

9. Whitbeck MG, Charnigo RJ, Khairy P, Ziada K, Bailey AL, Zegarra MM, et al. Increased mortality among patients taking digoxin —analysis from the AFFIRM study. Eur Heart J. 2013;34:1481-8.

10. Diaz-Guzman E, Mireles-Cabodevilla E, Arrossi A, Kanne JP, Budev M Amiodarone pulmonary toxicity after lung transplantation. J Heart Lung Transplant. 2008;27:1059-63. 